\title{
¡El futuro pertenece por entero al Comunismo! Influencias del cine de ciencia ficción de la URSS y de otros países del Este en el imaginario literario cubano
}

\author{
Future belongs to Communism! The influence of Eastern and Soviet Science \\ Fiction Cinema in Cuban Literary Imaginary
}

\author{
RAÚL AGUIAR \\ Centro de Formación Literaria Onelio Jorge Cardoso·raul@centro-onelio.cult.cu
}

Licenciado en Geografía por la Universidad de la Habana, es editor de la revista digital Qubit y de la revista Korad. Como escritor, sus cuentos han aparecido en numerosas antologías de Cuba y el extranjero y sus novelas han ganado distintos premios.

RECIBIDO: 16 DE FEBRERO DE 2015

ACEPTADO: 4 DE JUNIO DE 2015

Resumen: La ciencia ficción cubana, particularmente en los años 80 del siglo XX, resulta bastante diferente de la realizada en otros países de Latinoamérica. Este artículo trata de desentrañar la influencia que pudo tener en la configuración de tal especificidad el cine fantástico soviético estrenado en Cuba de manera regular desde 1961 hasta la desaparición de la URSS. El texto, por un lado, reconstruye cronológicamente la presencia del cine fantástico soviético en la isla. Por otro, aborda con detalle la influencia directa de tales películas en el imaginario fantástico de la literatura cubana. Lo hace a través de algunas obras esenciales del fantástico soviético .

Palabras Clave: ciencia ficción cubana, cine fantástico soviético, literatura cubana, Agustín de Rojas, Félix Lizarraga.

\begin{abstract}
Cuban science-fiction, especially in the 80 's, is quite different from the science-fiction written in other Latin countries. This paper tries to unravel the influence that fantastic Soviet films, which were regularly premiered in Cuba since 1961 until the demise of the USSR, could have had in shaping such specificity in Cuban literature. The text, firstly, reconstructs chronologically the presence of fantastic Soviet cinema in the island. Secondly, it addresses in detail the direct influence of such movies in fantastic Cuban literature. It does so through some essential works of Soviet fantastic.
\end{abstract}

Key Words: Cuban science-fiction, Soviet fantastic cinema, Agustín de Rojas, Féliz Lizarraga. 
Los cuentos y novelas de ciencia ficción cubana, debido a los condicionamientos históricosculturales propios de la isla -sistema socio-político imperante, embargo económico, dependencia económica ¿e ideológica? de los países del Este, sobre todo la URSS- resultan, sobre todo en la década de los 80, bastante diferentes al resto de las producciones escritas en otros países de habla hispana. Una gran parte de los libros publicados en Cuba en esta década resultan un híbrido de las influencias de la ciencia ficción escrita o filmada en los países de occidente (sobre todo de la escrita o filmada hasta los años 50, con Ray Bradbury e Isaac Asimov a la cabeza, en la literatura, y con La máquina del tiempo, La Mosca, Viaje al Centro de la tierra o la serie francesa de Fantomas, en el cine) y aquella otra importada desde los países del bloque socialista (Polonia, Bulgaria, la antigua RDA, Checoslovaquia, pero sobre todo de la Unión Soviética.

Es bastante complicado discernir cuánto hay de cine de ciencia ficción soviético o de los países socialistas del este en el fantástico literario o audiovisual cubano. A pesar de que en casi toda la década de los 70 no se publicó ningún texto de ciencia ficción cubano en nuestro país, los pocos filmes del género importados de los países socialistas, Japón o de Europa occidental, con la exclusión casi total del cine norteamericano, fueron generando un gusto por la ciencia ficción en una gran cantidad de jóvenes que luego se encargarían de rescatar el género para la literatura en la década siguiente. Los escritores de ciencia ficción cubanos no tuvieron la oportunidad, hasta bien entrados los años 80 , de visionar películas tan importantes como La naranja mecánica, 2001, una odisea espacial, Soylent Green o El planeta de los simios, por solo citar las más influyentes para el resto de los narradores de habla hispana.

La primera película soviética de ciencia ficción que sirvió de carta de presentación para el público cubano durante los años 70 fue El hombre anfibio, (Человек-Амфибия, 1961), de V. Tchabotaev у G. Kazanski, basada en la novela Ictiandro, de Alexander Beliaev. El filme trataba sobre las aventuras de un joven mutante, creado por la ingeniería quirúrgica de su padre, el doctor Salvator, ingeniería que le permite convertirse en un ser anfibio y respirar bajo el agua pues se le han injertado branquias de tiburón. Una película romántica, que constituyó un gran éxito de taquilla y propició el gusto de los aficionados del género por la cinematografía fantástica importada desde la URSS.

Un año después se proyectó en nuestros cines El planeta de las tormentas (Планета бурь, 1962), del director Pavel Klushantsev, basada en una novela de Alexander Kazantsev.

El planeta de las tormentas es el primera de tres películas sobre viajes espaciales que más van influir en la literatura de ciencia ficción cubana. En este filme, tres naves espaciales soviéticas se encuentran en misión hacia Venus. Una de ellas es destruida por un asteroide y toda la operación es puesta en peligro. La tripulación elabora un plan y deciden descender a Venus. Una vez que los astronautas llegan a la superficie del planeta deberán enfrentarse a monstruos prehistóricos, 


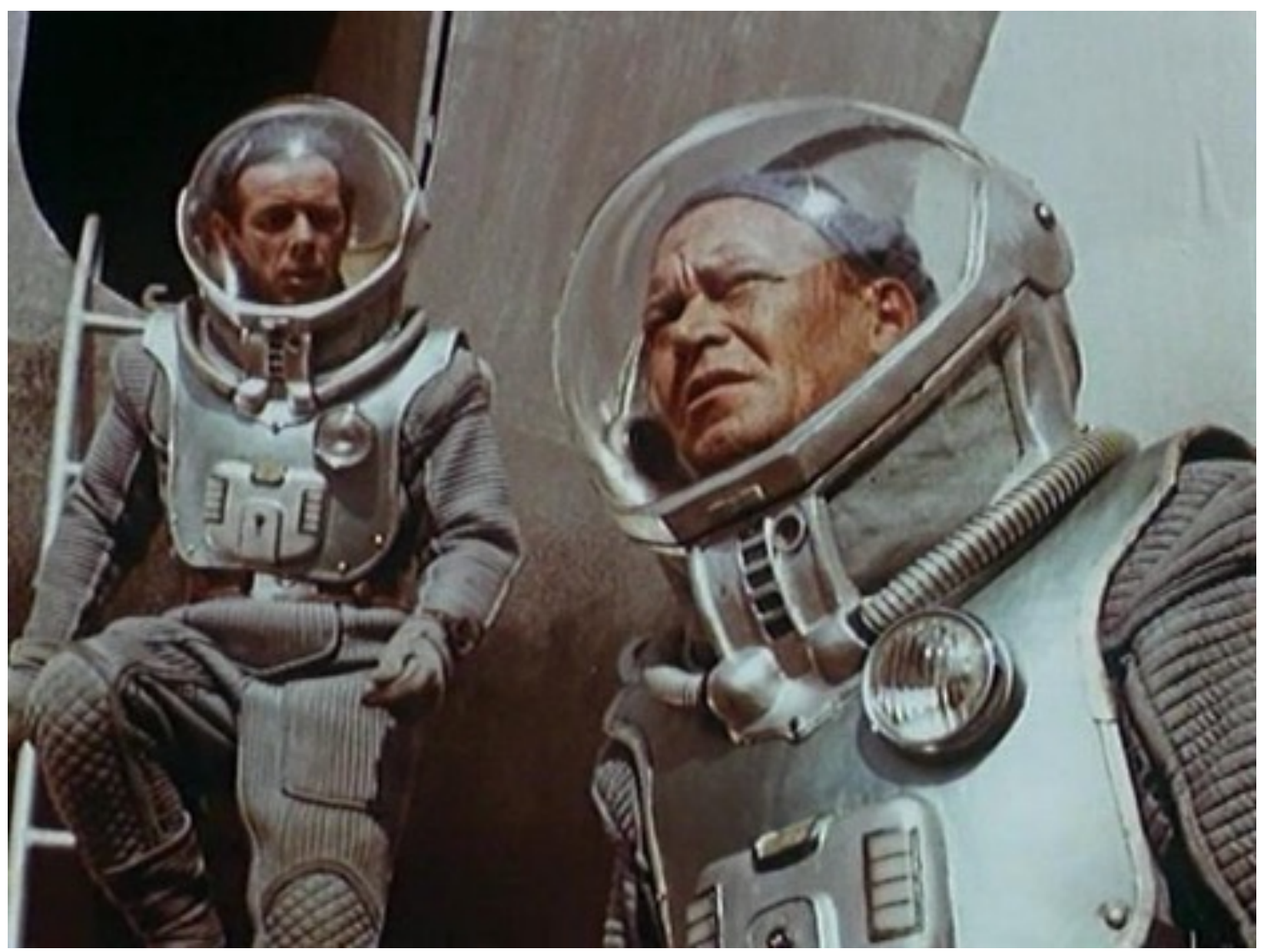

Elplaneta de las tormentas, Pavel Klushantev, URSS., 1962.

enfermedades y plantas carnívoras, además de descubrir los posibles indicios de una civilización ya extinguida.

El diseño de producción y los efectos especiales estaban bastante desarrollados para su época, no así el guión y los diálogos, todavía con un fuerte componente del Realismo socialista. Todos los tripulantes se comportan de una manera estrictamente estoica, con parlamentos que argumentan el orgullo y el deber de cumplir con la misión que el pueblo y el Partido Comunista de la Unión Soviética les ha encomendado.

La segunda de estas películas es La nebulosa de Andrómeda (Туманность Андромеды, 1967) del director Yevgeni Sherstobitov, con guión del propio Ivan Efremov, autor de la novela homónima publicada en 1957. 
En el futuro la humanidad vive en una sociedad utópica y pertenece a una comunidad de civilizaciones que intercambian información científica, conocida como El Gran Circuito. Aquí la utopía comunista pasa por una reencarnación de la cultura griega, con personas dedicadas a la ciencia, y aplicando un esquema de tutelaje entre jóvenes discípulos y veteranos maestros. Dedicados a la exploración del espacio, los científicos han lanzado la nave espacial Tantra, la cual se ha aproximado a investigar la llamada Estrella de Hierro. Pero el cuerpo celeste posee un poderoso campo gravitacional, y el Tantra se ve obligado a aterrizar en una de sus lunas, enfrentando la posibilidad de quedar varados durante 20 años a la espera de una misión de rescate. Sin embargo, la expedición ha descubierto una nave alienígena sin rastros de vida.

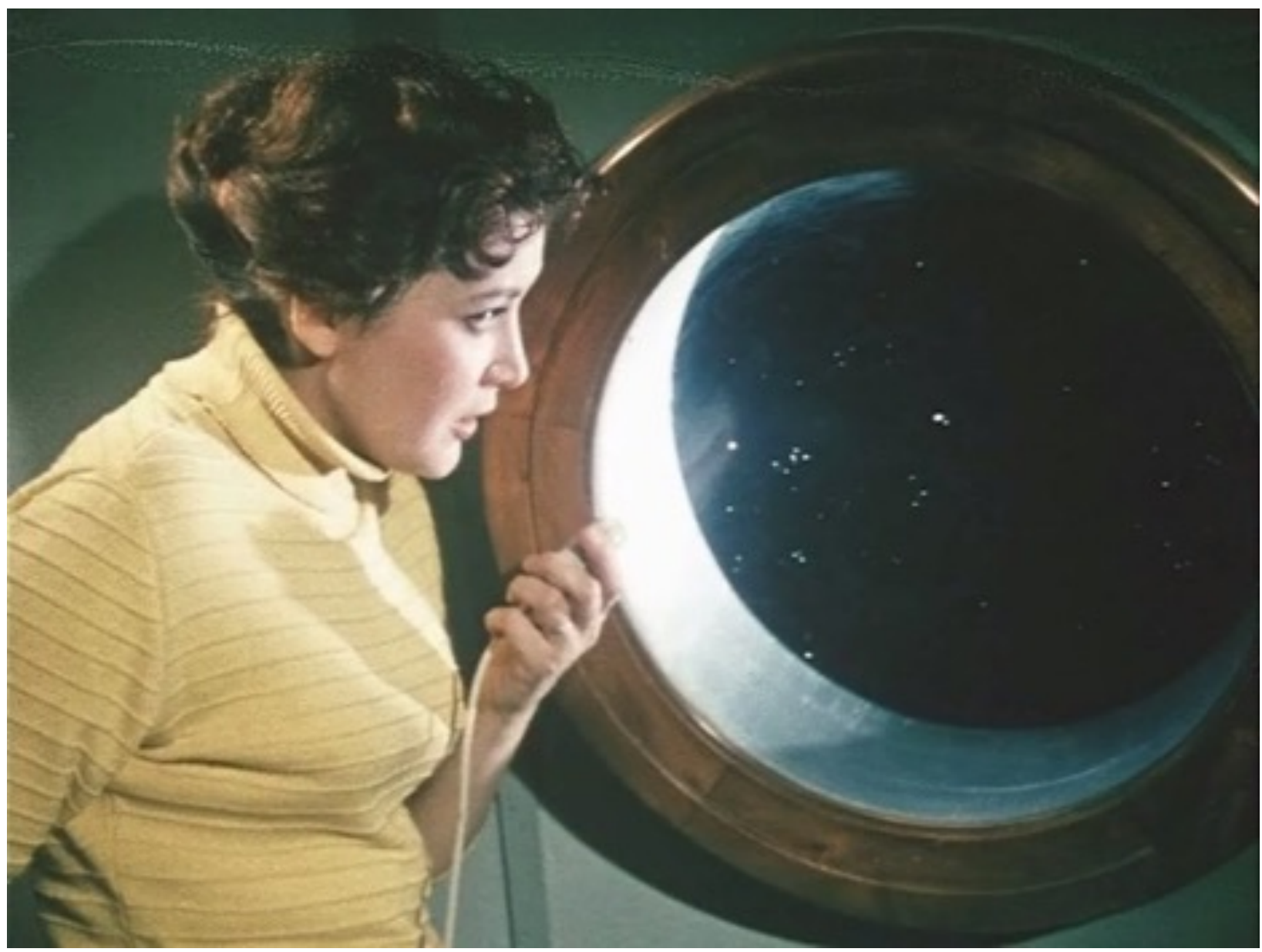

El planeta de las tormentas, Pavel Klushantev, URSS., 1962. 
Noor, el capitán de la expedición, ordena tomar suministros de la nave para reparar el Tantra y escapar... pero un ente sobrenatural invisible parece acosar a los humanos, atacándolos y devorando su carne. Ahora los astronautas deberán montar una improvisada defensa mientras investigan la naturaleza de la criatura. Como suele suceder en los filmes soviéticos de ciencia ficción, éstos son los momentos en que la película logra atrapar la atención del espectador en una trama repleta de discursos ideológicos y odas a la epopeya del hombre en el espacio.

Tal vez las influencias más explícitas de estos filmes sea, por una parte, la entrada de la ciencia ficción dura y el viaje espacial en las narraciones de algunos autores cubanos y, por otra, el optimismo a ultranza al concebir al ser humano en las sociedades futuras. Ángel Arango, uno de los pioneros del género en Cuba, afirmaba en un artículo publicado en la revista Unión en 1982:

Lo primero fue, sin duda, llegar a la comprensión de la razón cósmica que había en esa filosofía optimista. Independientemente de todos los riesgos que tengamos que afrontar en los estertores finales del imperialismo, es lo cierto que la conquista del cosmos requiere una Tierra pacífica, trabajando en cooperación, tanto desde el punto de vista moral como económico (en el sentido de la mejor utilización de los recursos). Aquí la moral y la realidad material se estrechan las manos. No se trata de una abstracción o una aspiración ética solamente, sino que la conquista del cosmos no es concebible sin una elevada moral. Ni un planeta dividido por la guerra ni un pueblo belicista irán más allá de sus narices en la conquista del espacio cósmico, por mucho que se esfuercen (Arango, 1982: 72).

El artículo en general es interesante porque parece una excusa un tanto forzada acerca del pesimismo latente en la obra anterior de Arango, pionero de la CF de los 60s, influido sobre todo por los relatos y novelas de Asimov y Bradbury pero indica, de alguna manera, la forma de pensar que asumieron muchos escritores de ciencia ficción cubanos en la década de los 80. Si en sus libros anteriores, era realmente difícil encontrar elementos de ciencia ficción dura en sus relatos, o de discursos acerca de un mundo utópico futuro, es a partir de su novela Transparencia, publicada en 1982, donde, supuestamente, corrige ese "defecto"

Las afirmaciones de principio a lo largo de la novela fueron conformándose de modo espontáneo, sin esfuerzo ni imposiciones del autor. Intencionalmente, a veces pude incluir párrafos que en otro contexto serían fórmulas discursivas de agitación política, de proselitismo (lo que comúnmente llamamos "teque"), pero fue hecho con tal convencimiento y en el momento oportuno que el relato camina por el borde del abismo sin precipitarse en él (Arango, 1982: 73). 
Transparencia es la primera novela de una trilogía, junto a Coyuntura (1984) y SIDER (1994) que van desarrollando todo el universo creado por Arango. La idea original proviene de un cuento $\dot{G} A$ dónde van los cefalomos? de su primer libro, del mismo nombre, publicado en 1964. Se trata de un ciclo cuyo tema principal es la sociedad del futuro, pero el papel preponderante de la historia está basado en las mutaciones que se producen en astronautas terrestres que han perdido todo contacto con su planeta natal. El alto desarrollo de la tecnología y la robótica provoca la transformación de los hombres en "Cefalomos", una especie de "tortas pensantes". Si aquel primer cuento era de corte pesimista, las novelas describen el proceso inverso; los seres mutados luchan por recobrar su condición humana.

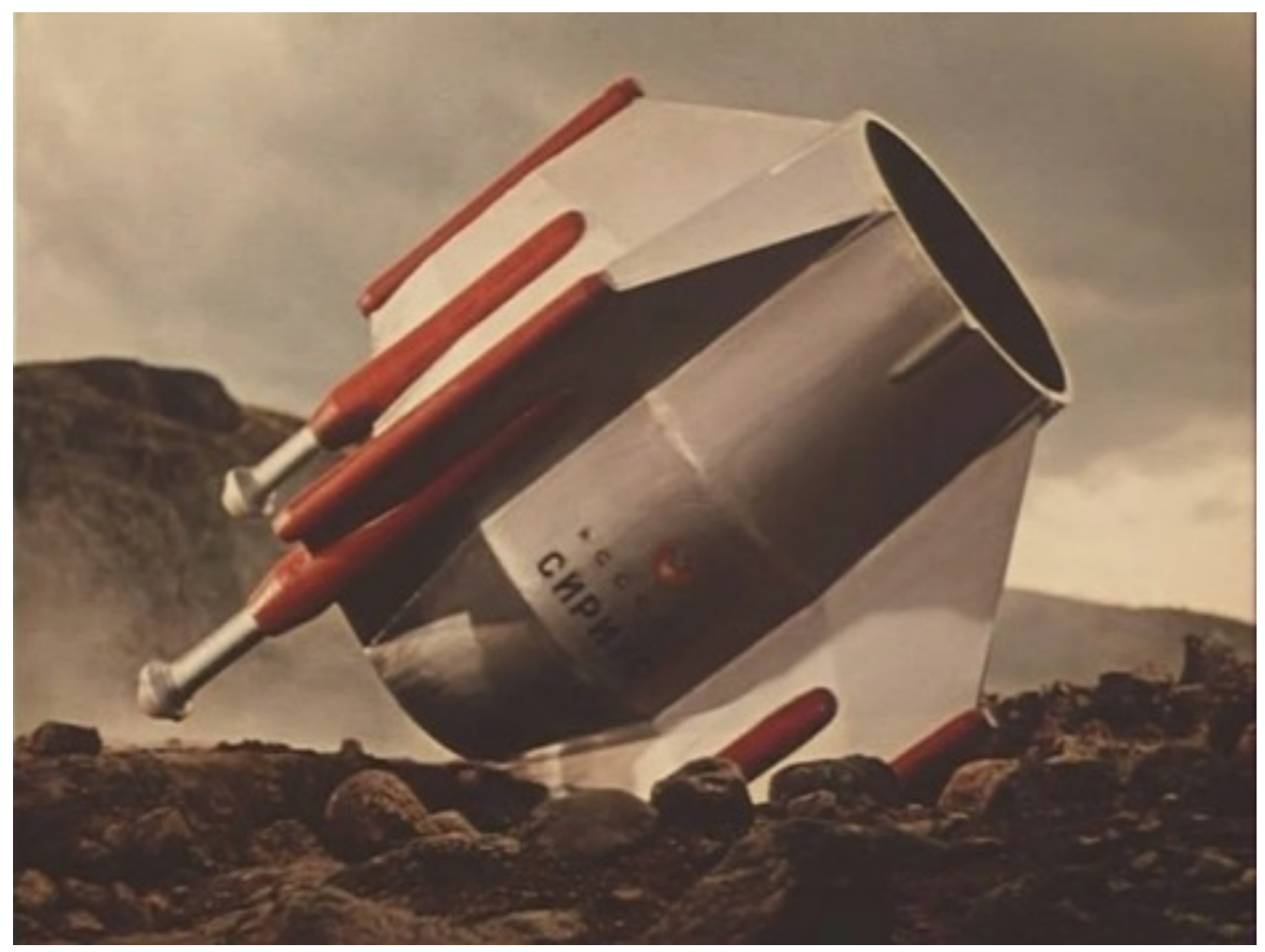

Elplaneta de las tormentas, Pavel Klushantev, URSS., 1962. 
En 1981 se publica Expedición Unión Tierra, del periodista cubano Richard Clenton Leonard. Libro denostado por muchos a causa de sus indudables desaciertos estilísticos y temáticos, demuestra una influencia bien marcada de la CF soviética.

La trama se desarrolla en una sociedad comunista futura, basada en un sistema social único y de comprensión mutua, donde hace 200 años, según palabras del autor

La Tierra también vivió crisis energética y por tanto quisieron desatar una devastadora guerra. Aquella conflagración se denominó "La guerra del combustible". Pero no procedió porque antes sobrevino una revolución que dio al traste con el capitalismo y la desigualdad en el sistema social. El petróleo fue sustituido por el átomo y este después por la energía solar (Clenton, 1981: 330).

La historia comienza en Moscú y su personaje protagónico es el cosmólogo Fiódor Martinov, caído en descrédito algunos años antes por afirmar, sin pruebas, haber descubierto un nuevo planeta situado en la franja de asteroides entre Marte y Júpiter. Luego se comprueba que el planeta, más grande que Júpiter, existe en realidad, y que sus habitantes quieren agredir la Tierra. Inmediatamente se organiza una expedición internacional llamada "Unión-Tierra”, y Fiódor es designado su comandante. Es de señalar que en toda la novela solo hay un personaje cubano, María, negra y cocinera de la expedición.

Al llegar al nuevo planeta, de nombre Fastón, se encuentran con que su civilización está dividida en tres castas: los funch, que han sido degradados hasta un nivel similar a la Edad de Piedra; los santorchanos, que viven esclavizados a un nivel cuasi medieval y los somis, amos y dueños del planeta, adelantados tecnológicamente y comandados por el gran Monstur, que desea exterminar a los terrestres para apropiarse de sus recursos y "dar paso a otras generaciones de somis, inteligentes y perfectos".

El resto de la novela es predecible. Los humanos ayudan a los santorchanos y somis "buenos" a rebelarse y derrocar a Monstur y sus acólitos del Alto Reinado. El ritmo de la narración se hace trepidante, casi de cómic, sino fuera por los parlamentos que muchas veces rozan el tono de panfleto.

Ya una vez en la Tierra existió un despreciable engendro como usted pero no alcanzó ver sus injuriosas ambiciones, fue aplastado por el curso de la historia (Clenton, 1981: 267).

-Ustedes no me entendieron -expresó Fiódor- hablé de la cohesión de nuestro planeta. No porque nos maten a nosotros piensen que lo habrán con la Tierra. Otros seguirán lo que nosotros comenzamos. Jamás creerán en la hegemonía del desarrollo tecnológico sobre las bases de la desigualdad y la explotación (Clenton, 1981: 370). 
Pero indudablemente el filme que más influyó en los escritores del género fue Solaris, (Солярис, 1971) ${ }^{1}$, de Andrei Tarkovski, basada en la novela homónima de Stanislaw Lem y que nunca se publicó en la isla. Esta versión de Solaris departe sobre las relaciones entre los seres humanos cuando se

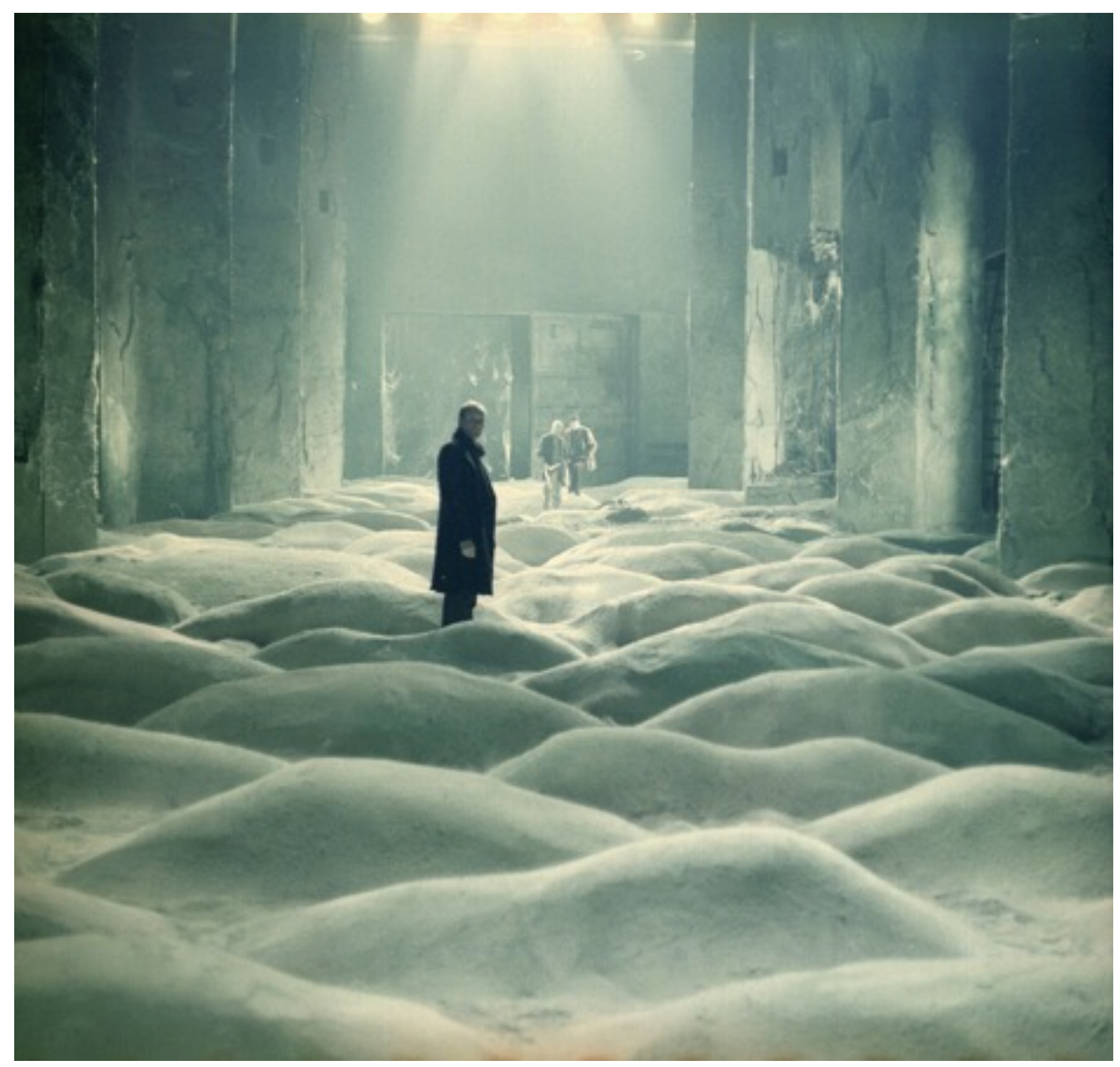

Stalker, Andrei Tarkovski, URSS, 1979.

${ }^{1}$ Existe otra versión estadounidense de 2002, dirigida por Steven Soderbergh. 
materializan los deseos más íntimos a la vista de los demás, como así también la inabordable tarea de relacionarse con lo desconocido.

El autor con mayor influencia de la literatura y el cine de ciencia ficción soviéticos es, sin dudarlo, Agustín de Rojas Anido, cuya primera novela, Espiral, ganó el Premio David de ciencia ficción en 1980, salió publicada en 1982 y constituye una de las mejores obras del género publicadas en Cuba. Un breve repaso a la trama nos puede dar una idea de estas influencias.

Al planeta Tierra, que ha sufrido numerosos trastornos como resultado de una hecatombe nuclear, regresa un grupo de jóvenes descendientes de una expedición enviada al Cosmos por la Federación Comunista unos días antes de la Catástrofe. Ha transcurrido mucho tiempo y aunque el peligro de la radiación ha disminuido hasta niveles tolerables, los actuales habitantes pueden ser peligrosos. Los astronautas proceden de un nuevo mundo -Aurora- y vienen a prestar ayuda a los sobrevivientes, así como investigar minuciosamente las causas de la destrucción parcial del planeta de sus progenitores. Es el sentido colectivo de la voluntad y el deber lo que signa la proyección individual de cada uno de los integrantes del equipo, para quienes lo más importante, aún a costa de la propia vida, es el éxito de la misión que se les ha encomendado.

Al mismo tiempo, un grupo de descendientes del Imperio (el Imperialismo ha logrado también salvar algunas expediciones enviándolas al espacio antes de la conflagración) está regresando a la Tierra con la misión de arrasar todo resto de vida en el planeta.

Una leyenda del futuro, la segunda novela de Agustín de Rojas, publicada en 1985, presenta una historia similar: en esta, un grupo de jóvenes parte en viaje de exploración hacia Titán, uno de los satélites de Saturno. Tras el choque de la nave espacial Sviagator (nótese el aroma ruso del nombre) con un aerolito, y la muerte de tres de los seis tripulantes, se impone a los sobrevivientes una labor casi imposible: el regreso de la nave, seriamente dañada, a la Tierra. Desde el inicio mismo de la novela, los personajes saben que van a morir: están expuestos a una radiactividad muy alta cuyas consecuencias pronto empiezan a hacerse evidentes. Saben que tienen contadas horas, pero se esfuerzan en lograr el retorno de la nave, al costo de su propia existencia con tal de cumplir la misión encomendada. Solo así se entiende la alegría de Isanusi, el jefe de la expedición, al ordenar que su cerebro sea integrado a la biocomputadora, ante la imposibilidad de ejercer sus funciones motoras y la necesidad de la reparación urgente de aquella, o la actuación de Gema cuando tiene que matar a Thondup, ya que los delirios de este ponen en peligro la seguridad de la nave.

En 1990 se publica la última novela de ciencia ficción de Agustín de Rojas, El año 200, que trata acerca del encuentro mortal entre los asesinos del Imperio - a quienes se suponía desaparecidos muchos 


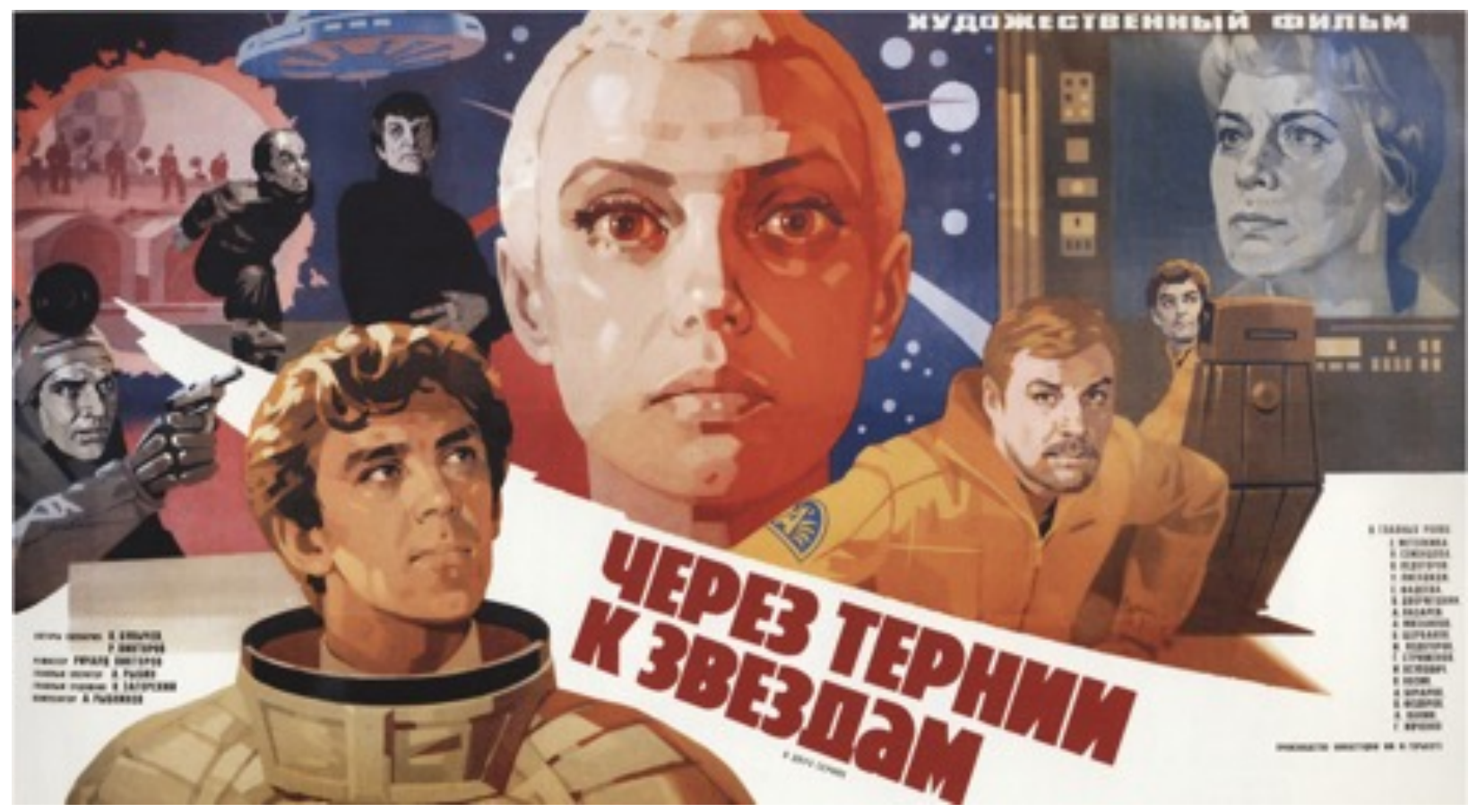

Camino a las estrellas. Pavel Klushantev, URSS, 1958

años atrás - y los hombres y las mujeres de una sociedad nueva surgida de la evolución comunista de la humanidad. Como en La nebulosa de Andrómeda, la novela nos traslada a una sociedad de altísimo desarrollo científico-técnico donde el trabajo creador es una necesidad primordial. Los principios éticos se enfrentan a los intereses egocentristas y triunfan.

Desde la caída del bloque socialista y los consiguientes cambios en Cuba, Agustín de Rojas dejó de escribir literatura de ciencia ficción y se dedica principalmente a los temas históricos. En 1997 obtuvo el Premio Especial de Novela Dulce María Loynaz con la novela histórica El publicano, que trata acerca de uno de los discípulos de Jesús.

Sus libros, agotados en librerías cubanas, y también devenidos en rarezas en bibliotecas públicas, constituyen, al decir de muchos críticos literarios, el punto más alto de la narrativa que incluye la ciencia ficción como tradición literaria y el deslumbramiento del hombre ante los progresos científico-técnicos.

Otro escritor donde se nota la influencia de esta obra maestra de Tarkovski es Félix Lizárraga. En El informe se valora una posibilidad de contacto con inteligencias extraterrestres de una manera poco comprensible para el hombre: con el estudio de su psiquis y, como en Solaris, con la proyección de esas imágenes del subconsciente. 
Beatrice, su noveleta que obtuvo el Premio David de 1981 es más audaz. La personaje principal es la copia exacta de una muchacha, pero no ha sido construida por el hombre, sino por una máquina, y como Hari, la personaje de Solaris, ella no se considera a sí misma como una máquina, sino como un ser humano.

La película Operation Bororo (Checoslovaquia, 1972), de Otakar Fuka, narra la lucha por la posesión de una panacea universal (cierto extracto de corteza descubierto por la tribu Bororo) entre dos extraterrestres y un grupo de asesinos a sueldo de una gran empresa farmacéutica capitalista, que teme que se les hunda el negocio si se difunde el uso del medicamento. Narrada al estilo policial, este filme encantó a muchos escritores del género, que vieron en ella por primera vez la versión de unos extraterrestres amistosos y que sirvieron de pauta para muchas narraciones de principios de los 80, ya que cumplía uno de los preceptos que debían regir en la supuesta "ciencia ficción socialista"; una

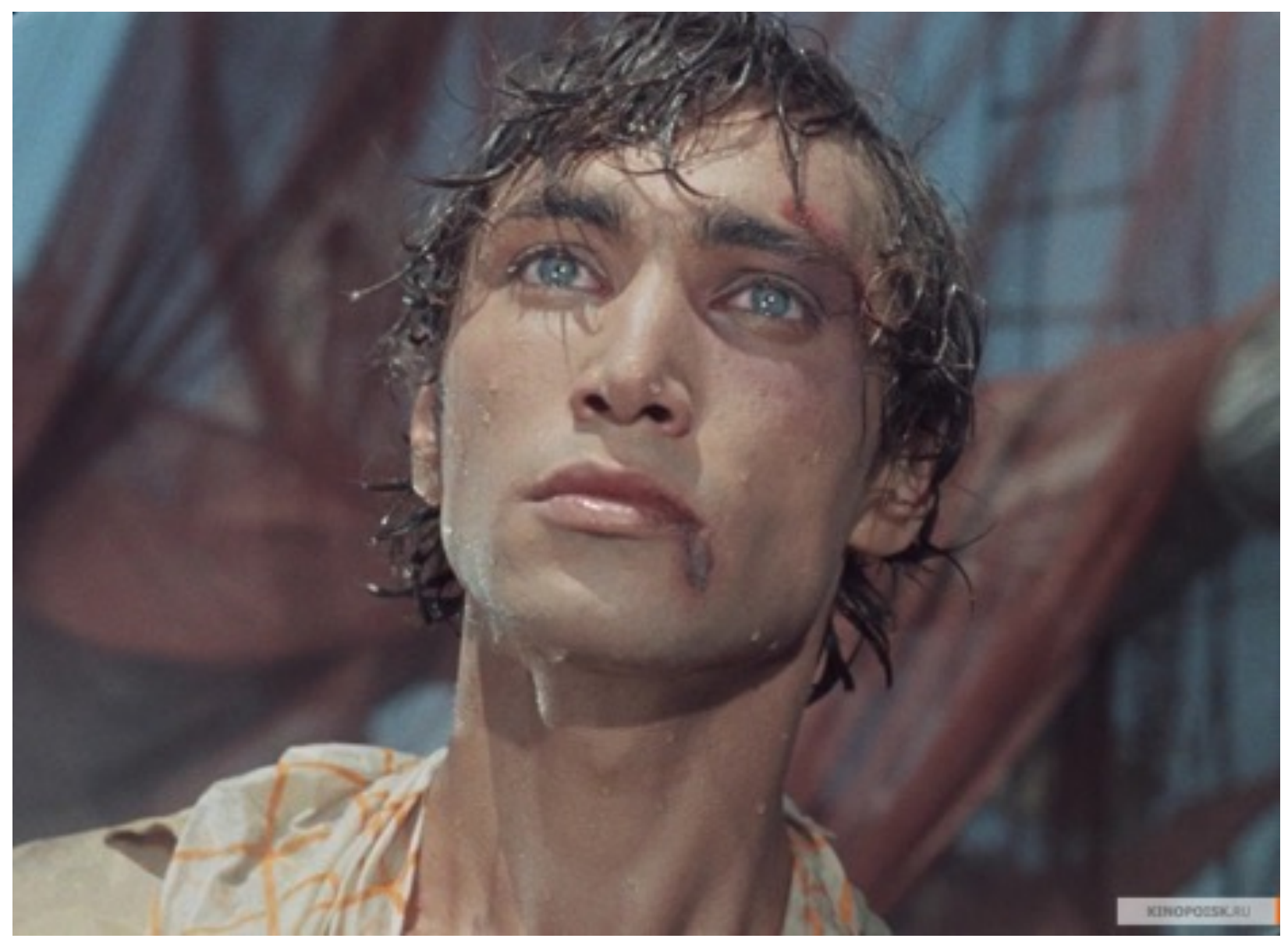

El hombre anfibio, Gennadi Kazansky, Vladimir Chebotaryov, URSS, 
civilización extraterrestre más avanzada o del futuro debía ser pacífica, ya que habrían eliminado todos los conflictos sociales y las desigualdades humanas.

Una influencia clara de esta película en la narrativa fantástica cubana es la novela Confrontación, editada en 1985, escrita a cuatro manos por Rodolfo Pérez Valero y Juan Carlos Reloba. Se trata de una mezcla poco común en el género: espionaje-ciencia ficción-policial.

Un importante descubrimiento cubano que habría de producir una revolución en materia de energía y alimentación, con el consiguiente beneficio de los países del tercer mundo, es codiciado por dos siniestras transnacionales imperialistas. Las acciones ocurren en un futuro cercano y no hay héroes individuales, sino que es la labor colectiva de los investigadores cubanos las que logran vencer a las pretensiones del enemigo. El conflicto es el de la mayoría de las narraciones de espionaje de la década: socialismo versus imperialismo y el mensaje es inequívoco y casi obligatorio: siempre saldrá adelante la causa justa de los pueblos, ante la pervertida astucia y la desarrollada tecnología de los imperialistas.

Similar mezcla de géneros, pero con la adición de una historia de amor, como en el filme Operación Bororo, logra Rafael Morante con una noveleta titulada Amor más acá de las estrellas, premio David 1984 y publicada en 1987.

En el malecón habanero aparece un cadáver con extrañas características. Un policía y una joven proveniente de una lejana fase espacio-temporal combaten contra una entidad maligna que se ha desviado, y esto es un caso excepcional, de los principios justos y racionales de su fase.

También en 1973 salen tres películas soviéticas que luego tendríamos oportunidad de disfrutar en Cuba: La primera de ellas es Ivan Vasilievich cambia de profesión (Иван Васильевич меняет профессию) del director Leonid Gaidai. Basada en un guión de Mijail Bulgakov, es una comedia ligera que trata sobre un viaje en el tiempo. Un profesor crea una máquina del tiempo y viaja a la corte de Iván el Terrible. El problema es que entonces Iván el Terrible ocupa su lugar en el presente.

Ya en la narrativa de ciencia ficción cubana, el tono de humor estaba presente desde sus primeros libros. Es una forma particular de humor criollo, propio de Cuba y México, que se ha dado en llamar "choteo". Aparece en La ciudad muerta de Korad, de Oscar Hurtado, en 1964, y El libro fantástico de Oaj, de Miguel Collazo, otro de los grandes pioneros del género. Durante los años 80, el humor sigue presente en una buena parte de los cuentos publicados en antologías y alcanza su mayor desarrollo en las novelas de F. Mond.

En su novela ¿Dónde está mi Habana? (1985), el humorista F. Mond lanza a su personaje David en un sueño 200 años al pasado, a la Habana colonial, donde introduce un personaje que ya había 
perfilado en sus cuentos: Monsieur Larx, un agente del planeta Korad, en realidad un sofisticado androide que cumple misiones filantrópicas en la Tierra. Este personaje reaparece en 1987 en Cecilia después o ¿por qué la Tierra?, y ya, a manera de saga, en sus libros posteriores Krónicas Koradianas (1988) y Vida, pasión y suerte (1999). Sus libros están dotados de una gran cubanía y el choteo cubano, con clara intertextualidad y apropiación de personajes históricos reales o imaginarios como el pionero de la aeronáutica cubana Matías Pérez o la Celicia Valdés, personaje central de una novela del siglo 19 de Cirilo Villaverde.

La segunda película de 1973 es El silencio del doctor Ivens, del director Budimir Metalnikov. Un accidente de avión provoca que Ivens, el protagonista, junto a otros sobrevivientes de la catástrofe, lleguen a una isla desierta donde hacen contacto amistoso con seres extraterrestres. Este filme se proyectó en Cuba en la misma época que se ponían de moda los temas relacionados con el paleocontacto y el Triángulo de las Bermudas y en varias antologías de ciencia ficción cubanas se pueden encontrar algunos cuentos bastante fieles a la trama de este filme.

Uno de los ejemplos más claros dentro de la narrativa cubana de ciencia ficción es el cuento "El otro mundo", de Eduardo Frank donde se narran los hechos acontecidos a un aviador que, fortuitamente, traspone algún indeterminado umbral entre dimensiones y arriba a un mundo desconocido donde imperan otras leyes físicas y biológicas. Del mismo Eduardo Frank es su cuento Solo la tundra lo sabe donde retoma la hipótesis de Alexander Kazantsev acerca de que el meteorito de Tunguska era una nave espacial extraterrestre que se estrelló en la Tierra. En 1987 publicó estos y otros cuentos en su libro Más allá del sol, premio David de CF de 1986.

Moscú-Casiopea (Москва-Кассиопея, 1973), del director Richard Victorov, alcanza cierta popularidad con una historia basada en el clásico viaje espacial. Un grupo de adolescentes es enviado a un planeta distante en la constelación Kassiopeia para ayudar su civilización. Esta es la primera de una trilogía de filmes del mismo director que versan alrededor del mismo tema Jóvenes en el cosmos (Отроки во вселенной, 1974) que relata la historia de unos muchachos que llegan a un planeta desconocido donde los robots han esclavizado a los seres vivientes y El espinoso camino hacia las estrellas (1980).

Trenco, novela de Roberto Estrada publicada en 1986 también trata sobre un grupo de jóvenes científicos y un viaje espacial. La misión tiene como objetivo visitar el planeta Trenco, donde llevarán a cabo un proyecto llamado "Comunicación universal", que consiste en experimentos telepáticos, para lo cual deben capturar un widgito, insectoide capaz de colocar a sus presas en un estado transitorio de obediencia psíquica, presas que hipnotizan telepáticamente antes de matarlas para succionar sus líquidos 
vitales. La expedición, como en otras tantas novelas de la época, es internacional, con personajes de diferentes países en los que no faltan un par de soviéticos, con el agregado de una extraterrestre oriunda de Rigel. Según el autor, en ese distante futuro

La humanidad ha progresado de tal manera que el hombre ha perdido casi el instinto de luchador característico de otras épocas menos felices (Estrada, 1986: 24).

Sin embargo, a pesar de que la Humanidad vive en una sociedad comunista, el autor, por boca de uno de sus personajes, aclara poco después:

Desgraciadamente aún subsisten formas de pensamiento y conducta ajenas a la realidad de la sociedad comunista actual. Los valores humanísticos de nuestra época son comunes a todos los hombres, pero es imposible pretender que todos respondan consecuentemente ante las múltiples situaciones de la vida. La infelicidad y el sufrimiento son todavía compañeras de la humanidad (Estrada, 1986: 40).

El planteamiento ya marca una gran diferencia y un paso de avance con respecto a las concepciones futuristas utópicas de, por ejemplo, La nebulosa de Andrómeda, o de otros autores cubanos anteriores. A pesar de estas dos citas anteriormente expuestas, los personajes de Estrada son mucho menos arquetípicos y sus parlamentos se mantienen fuera del tono discursivo o didáctico en la mayor parte de la trama, además de que el autor introduce algunos elementos fuertemente eróticos en la historia que no eran corrientes para la época, al menos en la vertiente de ciencia ficción dura.

Un año después, en 1987, sale publicado el libro Serpiente emplumada, de Arnoldo Aguila. Se trata de un libro de cuentos, algunos de ellos bastante interesantes como Rosas sin espinas, Medel y Hartmut, La pantalla negra y La serpiente emplumada.

En Rosas sin espinas, un grupo de norteamericanos, oriundos de New York, viajan en una máquina del tiempo al año 3195. Su objetivo es apropiarse de algunos objetos del futuro y llevarlos a su época para "hacer negocios." Allí se encuentran que su ciudad ha desaparecido y en cambio hay un inmenso prado lleno de flores donde se encuentra una niña. Inmediatamente los viajeros del tiempo le preguntan:

-¿Qué ha pasado aquí en Estados Unidos? ¿Por qué New York no es New York? ¿Ha habido guerra? ¿Dónde están los nuestros?

Y la niña les explica: 
Aquí hubo en los Años Duros una gran rebelión de las Flores contra las Espinas, y ganamos. Las Espinas querían sumir en el dolor de la herida a todos y las Rosas de aquí decidieron nacer sin Espinas, como ofrenda al Jardín Universal (Aguila, 1987: 20).

Luego la niña les regala dólares y un cofre lleno de oro, diamantes y piedras preciosas. Los viajeros se atemorizan por la capacidad que tiene la niña de leer los pensamientos y de crear cosas de la nada y se marchan atemorizados.

Medel y Hartmut tiene una gran influencia, no del cine de ciencia ficción soviético, sino de las películas sobre la Segunda Guerra Mundial que saturaron los cines cubanos durante las décadas de los 70 y 80 . Un cuento excelente, muy bien ambientado, con una caravana nazi que cruza una especie de umbral

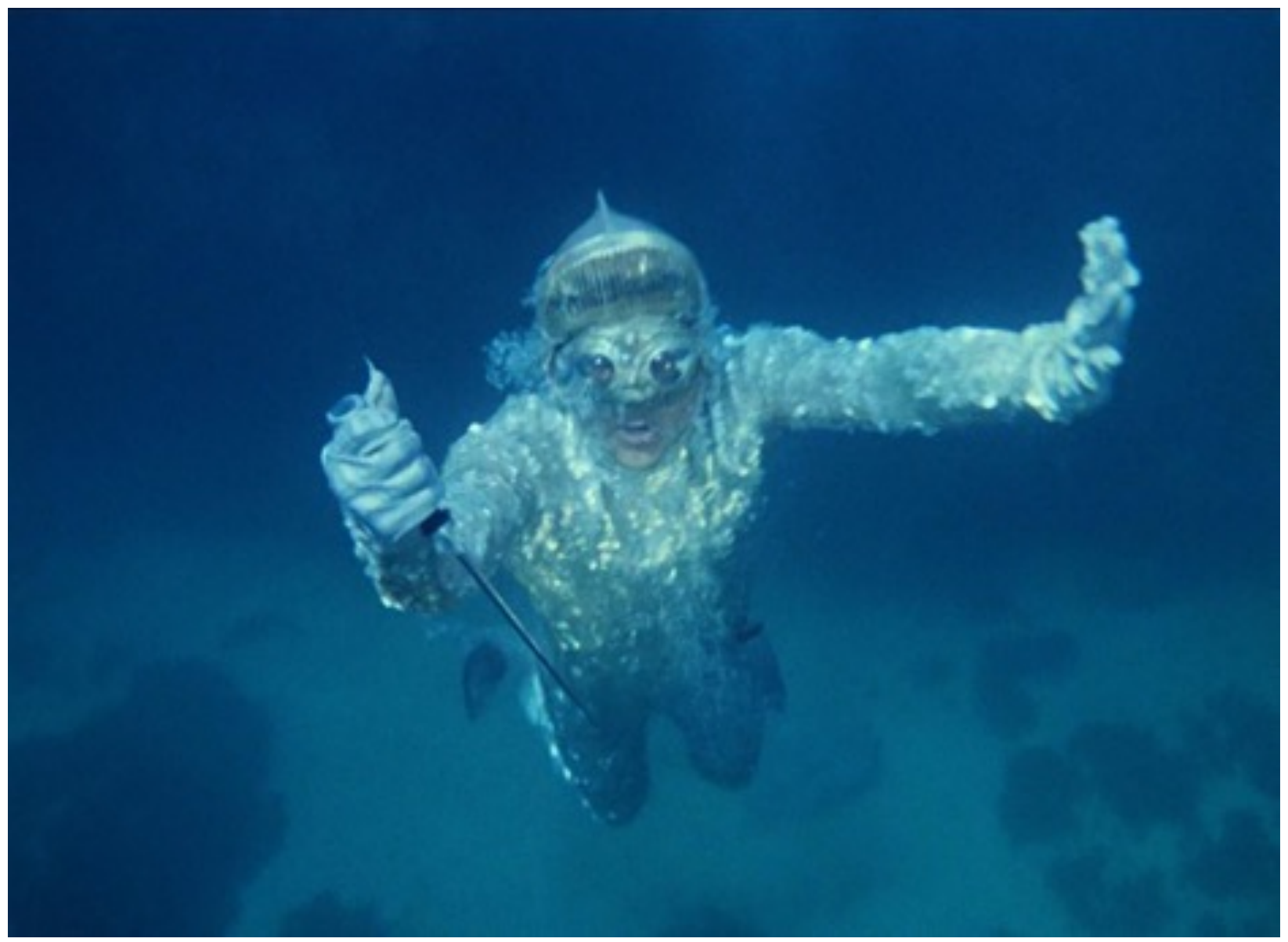

Elhombre anfibio, Gennadi Kazansky, Vladimir Chebotaryov, URSS, 1962 
inter-dimensional y van a parar a un universo paralelo donde al parecer existen sus dobles pero nunca ha tenido lugar el fascismo.

La pantalla negra vuelve a describirnos otra sociedad futura utópica, que se logró a partir de encerrar bajo una Cúpula gravitatoria al país de Usano, al frente del cual se encontraba "El Genocida" que intentó el llamado primer golpe atómico.

Abocada esa desdichada nación a tal tragedia por sus descabellados dirigentes, quedó aislada del resto del mundo de manera absoluta. El esfuerzo hecho con posterioridad para alterar este fenómeno no ha tenido éxito. Todos los estudios han llevado a la triste conclusión de que no puede haber vida debajo de la Cúpula.

Todos saben también que, después de aquel peligro, la humanidad entró en razón y hemos evolucionado hasta este mundo de paz con una forma social superior.

La serpiente emplumada es posiblemente el cuento más original de Arnoldo Águila. Trata sobre un grupo de físicos que deciden abandonar Terminal Cero, una estación orbital situada entre el planeta Mercurio y el Sol, porque han descubierto que en esta zona los campos magnéticos son tan intensos que se comportan como si tuvieran masa y ellos pueden entrelazar, como si tejieran, una especie de redes magnéticas a manera de las chinampas aztecas, y han revitalizado toda esa cultura ancestral creando una especie de ciudad gravitatoria a la que denominan Tenochtitlán II.

Como en Solaris, uno de los personajes es un inspector de la Tierra, enviado por el Gran Consejo, para analizar el trabajo de los físicos en el Sol y determinar su perspectiva futura, con la potestad de cerrar la estación y finalizar el experimento. En un momento de la historia se hace ver que "Los Hijos del Sol” como se autotitulan estos físicos, han estado ocultando información acerca de los peligros y la cantidad de muertes que ha provocado el experimento.

-¡Pero... usted está diciendo que nos han estado engañando! ¿En esta época?

Inmutable continuó Nguyen:

-Es cierto, querido colega: el engaño es una actitud superada por nuestra actual colectividad humana ya en una fase superior, cuando no existen fricciones como las originadas por los antiguos sistemas (...) Ellos saben que peligra su existencia como grupo y están convencidos de representar un camino extraordinario para la humanidad que no debe ser abandonado aunque perezcan todos, y saben que su peor enemigo lo constituye el número de bajas (Aguila, 1987: $100)$. 
También habría que mencionar Las aventuras del Electrónico (Приключения Электроника, 1980) serie de televisión en tres partes, del director Konstantin Bromberg. Fue emitida completa en dos ocasiones en la televisión cubana. La serie está basada en dos novelas El niño que vino en una caja y Ressy, el perro electrónico de Eugeny Veltistov. Un profesor crea un robot que es una copia exacta de la foto de un muchacho que vio en el periódico. El robot escapa y casualmente encuentra a su prototipo.

Esto va a crear muchos eventos cómicos que van a mantener la historia durante los capítulos de la serie. Habría que hacer referencia además a muchos dibujos animados del género que fueron televisados hasta la saciedad durante las décadas de los 70 y 80 en Cuba. En 1981 sale a la luz un largometraje de dibujos animados de ciencia ficción, El misterio del tercer planeta, del director Roman Katchanov, basado en el personaje de Alicia, una chica a quien nunca le sucede nada de muchos cuentos de Kir Bulithchev.

Este conjunto de películas, series televisivas y dibujados animados de ciencia ficción, con personajes protagónicos de niños o adolescentes y destinados a un público infantil y juvenil, eran visionados también por los escritores con gran interés y es lógico que también tuvieran su influencia en alguno de ellos como sucede con la novela Eilder, de Luis A. Soto Portuondo, premio David 1983 y publicada en 1987.

Eilder es el nombre de un adolescente de un distante sistema planetario, que llega a la Tierra huyendo de una sangrienta tiranía. Aparece en Cuba en la época de la novela, años 80, y allí recibe la ayuda necesaria para salvarse de sus perseguidores, una casta real de asesinos denominados Ejecutores, y regresa después a su planeta con una nueva visión acerca de la solidaridad y la disposición de enfrentar el régimen tiránico.

Esta novela ha sido ampliamente analizada en su vinculación a los preceptos del realismo socialista en el artículo "From Socialist Realism to Anarchist-Capitalism: Cuban Cyberpunk" del profesor Juan C. Toledano Redondo.

En 1979 Tarkovski reaparece con otro clásico de la CF cinematográfica mundial: Stalker, basada en un cuento de los hermanos Strugaski, "Picnic en la cuneta." Esta excelente película dio sin embargo a algunos autores la idea de que se podía escribir ciencia ficción "Sin efectos especiales", solo mediante una acción mínima y el diálogo "profundo” acerca de las grandes cuestiones ontológicas del ser humano.

De ello resultaron algunos relatos y novelas de puro diálogo didáctico, donde los científicos se las pasan de reunión en reunión, discutiendo cómo evitar determinada catástrofe, relatos lastrados por el tecnicismo excesivo, el conflicto humano diluido bajo los informes, las conferencias y las conversaciones 
Raúl Aguiar. Elfuturo pertence...

didácticas de personajes construidos como esquemas y que no lograban mantener la atención del lector más allá de la tercera cuartilla.

La nevada, de Gabriel Céspedes, premio David de 1982, publicada en 1985, sería el mejor ejemplo de una ciencia ficción sin "efectos especiales", casi al borde del género. Relata todo el proceso investigativo de un suceso inesperado en la isla: una nevada en la provincia de Matanzas, con el consecuente desarrollo de situaciones inesperadas como la muerte por congelamiento de una mujer y un hombre en la carretera, y el esfuerzo de sus personajes por crear un sistema predíctor de similares sucesos para el futuro. La obra se pierde en tecnicismos excesivos ya sea a través de una conferencia, algún informe o los diálogos. Los conflictos humanos quedan desplazados por la investigación en sí misma, con una progresión lenta, con intriga mínima y personajes de una sola pieza.

Si algunos de estos textos o fragmentos de los mismos se salvan como buena literatura se debe a que, por suerte, también están cruzados por otras premisas e influencias, además de la idiosincrasia y los estilos originales de los autores antes referidos.

Otros filmes destacables por su influencia son El test del piloto Pirx, (Test pilota Pirxa, 1979), también proyectada con éxito en los cines cubanos, una coproducción polaco-soviética, basada en un cuento de Stanislaw Lem, titulado "La encuesta.", donde se retoma el viejo tópico de los robots que en nada difieren de los seres humanos, excepto en los sentimientos y la sensibilidad humana.

El espinoso camino hacia las estrellas (Через тернии к звёздам, 1980), la tercera película de de Richard Victorov está basada en un guión de Kir Bulytchev. Unos astronautas encuentran una nave espacial extraterrestre con una muchacha a bordo. Ellos la aceptan de huésped. Su planeta, Dessa, está a punto de perecer por graves problemas ecológicos. La humanidad, conmovida, decide enviar una expedición de salvamento.

La última película soviética que tuvimos oportunidad de presenciar, ya en plena época de Gorbachov y su pereztroika, fue El poder de un dios (Es ist nicht leicht, ein Gott zu sein, 1989), basada en otra novela de los Strugatski, ¡Qué dificil es ser dios!, y escogida para ser llevada a la pantalla por el director alemán Peter Fleishmann, en una superproducción cuidada por alemanes, soviéticos, polacos y franceses.

Ya los escritores y aficionados de la ciencia ficción cubanos conocían de sobra el argumento ya que el libro había sido importado a Cuba en la década de los 70 y precisamente en los 80 se había emitido una serie de televisión con el título de Shiralad, con guión de Alberto Serret y Chely Lima, autores de CF de los 80, cuya trama era bastante similar en su esencia a la novela de los Strugatski. 
En la serie, debido a una catástrofe espacial, una joven y su androide deben aterrizar en Shiralad, planeta que vive en una época equivalente a la Edad Media terrestre y enfrentan el decursar histórico del planeta con una intensa trama de conjuras e intrigas cortesanas. Al final de la serie se conoce que ellos no son los primeros terrestres en arribar a Shiralad sino que el planeta ha estado sometido a un monitoreo histórico por la Tierra, todo dentro de una compleja paradoja de tiempo y espacio.

El cine ruso (post-soviético) de ciencia ficción sigue encontrando adeptos entre el público y los escritores del género en la isla. La saga de Guardianes de la noche (Ночной дозор, 2004) у Guardianes del día (Дневной дозор, 2006) de Timur Bekmambetov, basadas en la trilogía de Sergéi Lukiánenko o La isla habitada (Обитаемый остров, 2008) у su segunda parte La isla habitada 2: La batalla final, 2009) de Fyodor Bondarchuk, basada en la novela homónima de los hermanos Strugaski, abrieron de nuevo las puertas a una cinematografía que ya se había tornado lejana y con cierto sabor de nostalgia para los creadores de la isla.

Una vez hecha esta especie de desglose o cartografía temática, se podría especular acerca de que más allá de influencias, habría que hablar de confluencias entre las formas de pensar y crear, lógica consecuencia de los contextos históricos, ideológicos y culturales afines. Veinticinco años después del desplome de la URSS, todavía existen ciertas influencias en los autores cubanos acerca de los temas del Comunismo en el futuro, claro que ahora con otras premisas totalmente distintas a la que presentaban los escritores de los 80. Un buen ejemplo de ello es El alunizaje del 'Chango $1 y^{1 / 2}$ ', de Yoss, publicado en la revista virtual Qubit No. 51, donde en uno de los tantos universos paralelos propuestos por el autor, existe una línea temporal donde los soviéticos fueron los primeros en llegar a la Luna.

¿Victoria de la Verdad? Antes de que tenga tiempo de preguntarse qué coño hace una nave rusa iy con ese nombre de manual de marxismo de Konstantinov! posándose en la Luna, si el Vuelo Conjunto Soyuz- Apollo solo tendrá lugar años después y los soviéticos no tenían ningún cohete portador tan potente como el Saturno V de las misiones Apollo, la escotilla se abre con el inevitable poquito de aire de la esclusa escapando y condensándose en forma de escarcha, y salen dos cosmonautas en escafandras abultadas y tosquísimas marcadas con las siglas CCCP bajo la hoz y el martillo. En el pecho de la de uno dice YURI ROMANENKO, en el del otro puede leerse GEORGUI GRECHKO, y ambos bajan a pasos lentos, a la vez ligeros y torpes por la escalerilla, sosteniendo con gran cuidado un paquete que luego colocan sobre el fino polvo lunar... donde acto seguido comienza a desplegarse, mientras los dos cosmonautas se ponen en firmes y saludan militarmente a aquello que va revelándose como una estatua jinflable! de una persona en actitud heroica, con uniforme militar constelado de condecoraciones y un enorme bigote de cepillo (Sánchez/Yoss, 2010: 34). 
Otro ejemplo emerge de la obra reciente de uno de nuestros autores más jóvenes: Erick J. Mota, uno de los cultores de la tendencia que se ha dado en llamar CyberOrisha, a la creación de un cyberpunk eminentemente cubano.

En una línea temporal donde la guerra fría tuvo un resultado que llevó a Norteamérica al tercer mundo y a la URSS a vivir en el espacio, La Habana continúa en el mismo sitio frente al mar. Con una revolución ya olvidada y abandonada a su suerte por los rusos, con crisis de balseros provenientes de los antiguos Estados Unidos y un lago interior en medio de la ciudad, que recibe el nombre de Underguater. La ciudad se debate entre aseres, hackers, asesinos de la fundación Charles Manson, ejecutores abakuás,

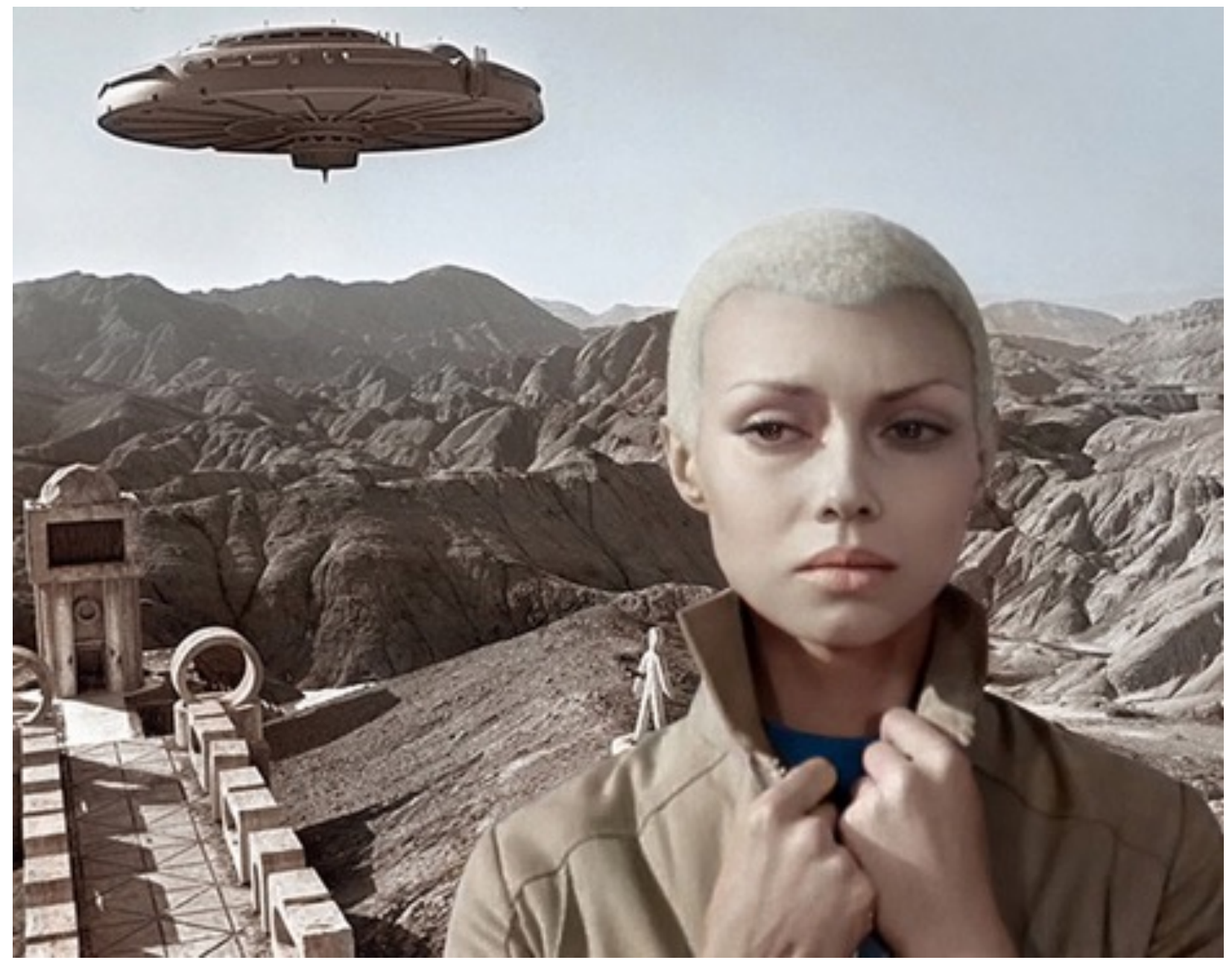

Camino a las estrellas. Pavel Klushantev, URSS, 1958 
piratas que buscan el oro de los rusos y soldados de la Fuerza Unida de La Habana Autónoma (FULHA). Es una Habana separada del resto de la isla, con la eterna vigilancia de los Estados Soviéticos del Espacio que amenazan todo el tiempo con dejar caer las bombas atómicas desde sus satélites. Muchos escogen el sueño soviético y hacen largas colas para subir a un cohete y despegar hacia las plataformas orbitales rusas, otros viajan a la tumba del Santo Guerrillero Ernesto Ché Guevara en Santa Clara Autónoma o prueban suerte conectados todo el tiempo a la Red Global, la tierra donde viven los Orishas. Este es, a vuelo de pájaro, el universo construido por Eric J. Mota en su libro de cuentos Algunos recuerdos que valen la pena, publicado en 2009 y su novela Habana Underguater, aún inédita.

Pero ya no hay aviones de combate en La Habana. Los rusos se los llevaron. Los muy hijos de puta. Prohibieron todo tipo de armamento estratégico, hundieron los portaviones americanos y se fueron para la órbita. Desde allí nos miran con sus bombas atómicas satelitales diciéndole al resto del mundo cómo se deben hacer las cosas. (...) Todos los días despegan cohetes. Cada tres horas. Repletos de gente que paga cuanto puede reunir, rapiñar y hasta robar, por un pasaje hacia la tierra prometida. Las plataformas geoestacionarias de los rusos. El sueño soviético, el modo de vida de los rusos en el espacio. (...) Hubo un tiempo en que también nosotros creíamos en el sueño soviético de la sociedad utópica en el Cosmos. Ya no. Los rusos se fueron y nos dejaron embarcados en el planeta. Solos y a nuestra suerte. ¡Rusos de mierda! (Mota, 2009: 35). 


\section{Bibliografía}

Aguila, Arnoldo (1987). Serpiente emplumada. La Habana: Editorial Letras Cubanas.

Arango, Ángel (1994). Sider. La Habana: Ediciones Unión.

Arango, Ángel. “El optimismo natural”. Unión 3 (1982): 70-74.

Arango, Ángel. (1984). Coyuntura. La Habana: Ediciones Unión.

Arango, Ángel. (1982). Transparencia. La Habana: Ediciones Unión.

Arango, Ángel. (1964). ¿A dónde van los cefalomos? Varios. La Habana: Cuadernos R.

Céspedes Borrell, Gabriel (1985). La nevada. Ciudad Habana: Ediciones Unión.

Clenton Leonard, Richard (1981). Expedición Unión Tierra. La Habana: Editorial Letras Cubanas.

Estrada, Roberto (1986). Trenco. La Habana. Editorial Letras Cubanas.

Frank R., Eduardo(1987). Más allá del sol. La Habana: Ediciones Unión.

Lizárraga, Félix (1981). Beatrice. La Habana: Ediciones Unión.

Mond., F. (1985).¿Dónde está mi Habana? La Habana. Editorial Letras Cubanas.

Mond., F.. (1987). Cecilia después o đ:por quéla Tierra?. Ciudad de la Habana: Editorial Gente Nueva.

Morante, Rafael (1987). Amor más acá de las estrellas. La Habana: Ediciones Unión.

Mota, Eric J. (2009). Algunos recuerdos que valen la pena. Ciudad Habana. Editorial Abril.

Pérez Varelo, Rodolfo y Reloba, Juan Carlos (1985). Confrontación. La Habana. Editorial Letras Cubanas.

Rojas Anido, Agustín de (1997). El Publicano. La Habana: Letras Cubanas.

Rojas Anido, Agustín de. (1990). El año 200. Ciudad de la Habana: Editorial Letras Cubanas.

Rojas Anido, Agustín de. (1985). Una leyenda del futuro. Ciudad de la Habana: Editorial Letras Cubanas. 
Rojas Anido, Agustín de. (1982). Espiral. Ciudad de la Habana: Unión de Escritores y Artistas de Cuba. Román, N. V. (2005). Universo de la ciencia ficción cubana. La Habana: Ediciones Extramuros.

Soto Portuondo, Luis A. (1987). Eilder. La Habana: Ediciones Unión.

Sánchez, José Miguel (Yoss) (2010). “Elalunizaje del Chango 1 y 1/2”. Revista Qubit No.51. Octubre.

Toledano Redondo, Juan C. (2005). "From Socialist Realism to Anarchist-Capitalism: Cuban Cyberpunk”. Science Fiction Studies (\#96, Volume 32, Part 2, July 2005, pp. 442-446) 